\title{
MYELODYSPLASTIC SYNDROME / SECONDARY ACUTE MYELOID LEUKEMIA: ROLE OF THE ALLOGENEIC HEMATOPOIETIC STEM CELL TRANSPLANTATION
}

\author{
Yhasmine Delles Oliveira Garcia' , Juliene Lima Mesquita' ${ }^{1}$ Yensy Mariana Zelaya Rosales ${ }^{1}$, Anna \\ Thawanny Gadelha Moura', Beatriz Stela Gomes de Sousa Pitombeira Araujo², João Paulo de \\ Vasconcelos Leitão², Karine Sampaio Nunes Barroso ${ }^{2}$, Lívia Andrade Gurgel ${ }^{2}$, Francisco Dario Rocha \\ Filho $^{3}$, João Vitor Araújo Duarte ${ }^{4}$, Isabella Araújo Duarte ${ }^{4}$, Beatrice Araújo Duarte ${ }^{4}$, Romélia Pinheiro \\ Gonçalves Lemes ${ }^{5}$ Fernando Barroso Duarte ${ }^{3,6}$.
}

\begin{abstract}
'Discente Programa de Pós-Graduação em Ciências Farmacêuticas da Universidade Federal do Ceará. Fortaleza, Ceará, Brasil. ${ }^{2}$ Médico (a) do serviço de Hematologia do Hospital Universitário Walter Cantídio, Fortaleza, Ceará. Brasil. ${ }^{3}$ Centro de Análises Clínicas (CAC) - Fortaleza (CE), Brasil. ${ }^{4}$ Aluno do Centro Universitário Christus-Fortaleza (CE), Brazil. ${ }^{5}$ Professora Titular do Departamento de Análises Clínicas da Faculdade de Farmácia da Universidade Federal do Ceará. Fortaleza, Ceará, Brasil. ' Professor Adjunto do Departamento de Cirurgia e Chefe do Serviço de Transplante de Medula Óssea da Universidade Federal do Ceará. Fortaleza, Ceará, Brasil.
\end{abstract}

Correspondence to: Fernando Barroso Duarte - nutriquimio@uol.com.br

\begin{abstract}
Secondary Acute Myeloid Leukemia (s-AML) refers to the development of leukemia after cytotoxic therapy, immunosuppressive therapy, radiation or an antecedent hematological disorder, such as Myelodysplastic Syndrome (MDS). A s-AML corresponds to $10 \%$ to 30\% of $A M L$ cases and is defined by the presence of at least $20 \%$ of blast cells, representing a category of disease with a poor prognosis. Allogeneic hematopoietic stem cell transplantation (Allo-HSCT) is the only option with curative potential for patients with s-AML, but recurrence after HSCT emerges as a frequent cause of treatment failure and course with high mortality. We report the case of a patient with s-AML after MDS, who underwent HSCT due to refractoriness to other treatments, recovering the bone marrow with dysplasia, being classified as AREB1.
\end{abstract}

Key words: Secondary Myeloid Leukemia; Myelodysplastic Syndrome;Autologous Hematopoietic Stem Cell Transplantation; Relapse; Diagnosis

\section{INTRODUCTION}

Myelodysplastic Syndromes (MDS) are an hematological disease characterized by peripheral cytopenias and displaced changes in the bone marrow which present progress of approximately one third of patients to acute myeloid leukemia (AML). The distinction between AML and MDS consists mainly on cytomorphological analyzes, since MDS has variable hematopoiesis and myeloblast count is less than $20 \%$, while s-AMLs' myeloblasts are $\geq 20 \%[1,2] \mathrm{HEU}$ NG et al., 2019]) .

The s-AML is different from the AML de novo, due to previous exposure to chemotherapy and / or radiotherapy treatments, secondary to diseases such as
MDS, Chronic Myelomonocytic Leukemia (CMML), Chronic Myeloid Leukemia (CML), and other variables. The s-AML has a less effective response to induction therapy, with a higher recovery rate and a worse prognosis $[4,5]$, which causes factors, such as: presence of comorbidities, drug resistance, justified cytogenetic and molecular changes or worse prognosis of AML compared to AML de novo.

Allogeneic hematopoietic stem cell transplantation (Allo-HSCT) is the only potentially curative option for patients with s-AML secondary to MDS, being indicated in primary induction failure or relapse refractory to chemotherapy $[4,7]$. However, for patients not eligible for HSCT, the treatment of choice is with 
Hypomethylating Agents (HMA), such as low-dose cytarabine or supportive care.[7,8].

The clinical management of these patients is a major challenge. Thus, the aim of this study was to report the case of a patient diagnosed with Acute Myeloid Leukemia secondary to Myelodysplastic Syndrome, treated with chemotherapy and submitted to Allo-HSCT, with relapse before six months and in the reassessment presented bone marrow with dysplastic morphological changes, being classified as AREB1 MDS, according to the WHO classification.

\section{Clinical Case}

Patient, male, 38 years old, came to our service in July 2018, asymptomatic, with a history of papulo-erythematous lesion on the first finger of his right hand and with laboratory tests that showed anemia ( $\mathrm{Hb}: 8.2 \mathrm{~g} / \mathrm{dL}$ ) with anisocytosis, leukopenia (1500/ $\left.\mathrm{mm}^{3}\right)$ and neutropenia $\left(225 / \mathrm{mm}^{3}\right)$. The initial treatment was with vitamins B1 (thiamine nitrate), B6 (pyridoxine hydrochloride), B12 (cyanocobalamin) and folic acid. Upon returning in September of the same year, he maintained anemia ( $\mathrm{Hb}: 8.1 \mathrm{~g} / \mathrm{dL}$ ) and neutropenia $\left(404.8 / \mathrm{mm}^{3}\right)$. The myelogram was performed and showed hypercellularity, with dysplasias in about $60 \%$ of the cells in the three hematological lines and $23 \%$ of blasts (Figure 1, immunophenotyping showed positive markers for CD13, CD33, CD34, CD45 and CD117, BCR-ABL and FLT3 were negative and the karyotype without structural changes (46
$\mathrm{XY}$ ).At the time, he was diagnosed with Acute Myeloid Leukemia with FAB maturation, LMA M2, secondary to MDS. Treatment was started with chemotherapy following the $3+7$ protocol with cytarabine and idarubicin and the MEC protocol (mitoxantrone, etoposide and cytarabine). The patient was refractory to treatment, being indicated for the realization of the HSCT.

The allogeneic related bone marrow transplant was performed in April 2019 with the reduced intensity conditioning regimen (RIC) with BUFLU (Busulfan and Fludarabine). The patient evolved with acute Graft Versus Host Disease (GVHD) in the skin, grade IV and in the fourth month after HSCT, still undergoing immunosuppressive therapy, pancytopenia with anemia was observed ( $\mathrm{Hb}: 10.8 \mathrm{~g} / \mathrm{dL}$ ), leukopenia $\left(1189 / \mathrm{mm}^{3}\right)$ and thrombocytopenia $\left(35,580 / \mathrm{mm}^{3}\right)$. The myelogram showed dyserythropoiesis and dysmegakaryopoiesis $>20 \%$ and the presence of $6 \%$ of explosions (Figure 2). Bone marrow biopsy showed hypocellularity, with hypoplasia and dysplasias $\geq$ $10 \%$ of the erythroid, granulocytic and megakaryocytic series and absence of fibrosis. An immunophenotyping with $7.7 \%$ of immature cells and HPN clones in less than $40 \%$. The patient was then reassessed and confirmed the diagnosis of MDS AREB1, stratified according to the score (IPSS-R) as high risk, and the use of Azacitidine was started, at a dose of $75 \mathrm{mg} / \mathrm{m}^{2}$ for 5 days. Currently, the patient is stable, with $(\mathrm{Hb}: 12.4 \mathrm{~g} / \mathrm{dL})$, leukocytes $\left(3100 / \mathrm{mm}^{3}\right)$ and platelets $\left(180,000 / \mathrm{mm}^{3}\right)$.
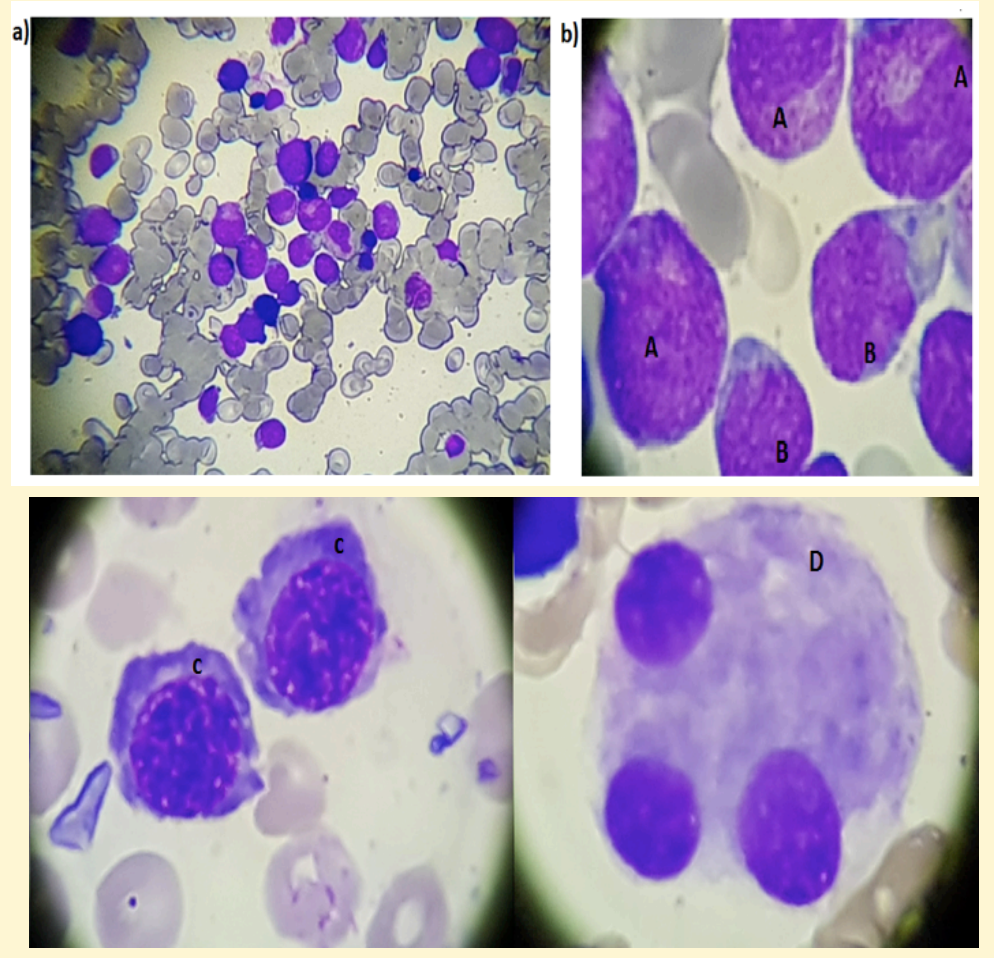

FIGURE 1- a) Hypercellular bone marrow for the age, with dysplasias in the three hematological lines: erythroid (6\%), granulocytic (20\%) and megakaryocytic (30\%) with dysplasias in about $6 \%$ of the cells, presence of $23 \%$ of blasts suggestive of AML. b) Myelogram at diagnosis, hypercellular medullary aspirate with the presence of $52 \%$ normal promyelocytes $(A)$ and $9 \%$ myeloblasts (B) with regular nuclei, some with nucleoli present and Auer rod.

FIGURE 2 - Myelogram after Allo-TCTH. C: Dysplastic erythroblasts with maturative asynchrony. D: dysplastic megacarioblasts. 


\section{Discussion}

MDS affects individuals of all age groups, being more prevalent in the elderly, on average of 65 to 70 years old, being characterized by the association of dysplastic hematopoiesis and peripheral cytopenias. Usually the patient is diagnosed with anemia, accompanied by thrombocytopenia; often, in the first stage, they are asymptomatic. It is noteworthy that MDS can progress to acute myeloid leukemia (AML), in about 20 to $30 \%$ of cases, 1 to 2 years after diagnosis, being more common in patients with high-risk MDS (MALCOVATI et al ., 2006; YE et al., 2019) [1,9].

Therefore, s-AML with MDS are associated with worse prognosis, when related to de novo or primary $A M L$, since studies demonstrate low rates of remission to conventional treatments and HSCT (BARRET et al., 2010 SENG SAYADETH et al., 2018; NOMDEDEU et al., 2017). [8, 10]

The patient was asymptomatic, at the first consultation, with laboratory of anemia, neutropenia and thrombocytopenia which after three months evolved to AML-M2. The patient was refractory to conventional chemotherapy treatment. When performing the HSCT, he evolved with GVHD grade IV on skin. Four months after HSCT, the patient was reassessed with a laboratory compatible with MDS AREB1, stratified according to the score (IPSS-R) as high risk, and the use of Azacitidine was started. Currently, the patient is stable with mild anemia and leukopenia and without transfusion dependence.

The incidence of relapse was 37\%, in two years, in patients with s-AML with SMD after HSCT, with overall survival (OS) exceeding $45 \%$ of the cases with RIC or MAC conditioning regimen, in which GVDH is one of the post-transplant complications in 39\% of patients (SENGSAYADETH et al., 2018) [10].

Many factors can be attributed to justify the failure of the HSCT in this case. The relapse of the primary disease can occur after the HSCT, if the initial conditioning regimen is insufficient as it does not establish an effect of the graft against the neoplastic condition. It is also noteworthy that it can occur after the period of effective catching, if the immune system weakens or becomes tolerant to residual disease, or if the disease suffers immune escape through the clonal selection of immune-resistant parents. In addition, it must be known that, occasionally, the disease may recur, in the donor cells, as an event de novo, masked as a relapse (BARRET et al., 2010).

Hypomethylating agents (azacytidine, decitabine) alone or in combination with donor lymphocyte in- fusion (DLI) appear to be among the most promising therapeutic options for the treatment of post-transplant relapse due to the direct antileukemic efficacy and immunomodulatory capacity of this therapy. Other treatment options for these cases are intensive chemotherapy or second HSCT, something for patients who do not achieve complete remission or long-term remission (Granfeldt et al., 2015). [11] In this case, the patient is being treated with hypomethylation and with prospects of performing a second HSCT.

Therefore, this clinical case demonstrates a rare event, with challenges related to treatment since there is no protocol to be followed for the relapse to primary disease.

\section{REFERENCES}

1. Malcovati L, Della PMG, Cazzola M. Predicting Survival And Leukemic Evolution In Patients With Myelodysplastic Syndrome. Haematologica. 2006; 9:1588-1590.

2. Walter MJ, Shen D, Ding LShao, et al. Clonal Architecture of Secondary Acute Myeloid Leukemia. N Engl J Med. 2012;

3. Cheung E, Perissinotti AJ, Bixby DL, et al.The leukemia strikes back: a review of pathogenesis and treatment of secondary AML Ann Hematol. 2019;98:541-559.

4. Sperling AS., . Gibson CJ, Ebert BL. The genetics of myelodysplastic syndrome: from clonal hematopoiesis to secondary leukemia. Nat Rev Cancer. $2017 ; 17: 5-19$.

5. Dan C, Chi J, Wang L. Molecular mechanisms of the progression of myelodysplastic syndrome to secondary acute myeloid leukaemia and implication for therapy. Annals of Medicine. 2015; 47: 209-217,

6. Kumar CC. Genetic abnormalities and challenges in the treatment of acute myeloid leukemia. Genes Cancer. 2011;2:95-107.

7. Rautenberg C, Germing U, Haas R,et al. Recidiva da leucemia mielóide aguda após transplante alogênico de células-tronco: prevenção, detecção e tratamento. Int J Mol.Sci. 2019; 20: 228,.

8. Barrett AJ, Battiwalla M. Relapse after allogeneic stem cell transplantation. Expert Rev Hematol. 2010;3:429-441. 
9. Ye Xingnong, Chen D, Zheng y, et al. The incidence, risk factors, and survival of acute myeloid leukemia secondary to myelodysplastic syndrome: $A$ population-based study. Hematological Oncology. 2019;37:438-446.

10. Sengsayadeth S, Gatwood KS, Boumendil A, et al. Conditioning intensity in secondary AML with prior myelodysplastic syndrome/myeloproliferative disorders: an EBMT ALWP study. Blood Adv. 2018;2: 2127-2135,.
11. Granfeldt Ostgard LS, Medeiros BC, Sengeløv H, et al.. . Clin Oncol. 2015; 33: 3641-9;

12. Duarte FB, Santos TEJ, Barbosa MC, et al. Relevance of prognostic factors in the decision-making of stem cell transplantation in Myelodysplastic Syndromes. Rev. Assoc. Med. Bras. 2016; 62:25-28.. 